\title{
Apatite sulfur isotope ratios in the 1257 Samalas eruption (Indonesia)
}

\author{
R. ECONOMOS ${ }^{1 *}$, Y. JACKSON ${ }^{1}$, S. DING ${ }^{2}$, A. FIEGE ${ }^{3}$, \\ C.VIDAL ${ }^{4}$ I. PRATOMO 5 , A. T. HERTWIG ${ }^{6}$, M.-A. \\ LONGPRÉ ${ }^{2}$
}

${ }^{1}$ Southern Methodist University, Dallas, TX, USA

(*reconomos@smu.edu)

${ }^{2}$ CUNY Queens College, Flushing, NY, USA

${ }^{3}$ American Museum of Natural History, New York, NY, USA

${ }^{4}$ University of Cambridge, Cambridge, UK

${ }^{5}$ Geological Museum, Bandung, Indonesia

${ }^{6}$ UCLA, Los Angeles, CA, USA

The 1257 eruption of Mt. Samalas in Indonesia produced sulfate anomalies in bi-polar ice cores that are $\sim 2$ times larger than those of the 1815 eruption of neighboring Tambora volcano, despite the similar magnitude of both eruptions ${ }^{1}$. The build-up of such a large volume of eruptible sulfur is likely to be related to pre-eruptive degassing and magma redox conditions. Information about these processes can be preserved in apatite crystals, which integrate sulfur as a trace element at concentrations that allow for $\delta^{34} \mathrm{~S}$ isotope ratio characterization in-situ via Secondary Ionization Mass Spectrometry ${ }^{2}$.

We investigated apatite crystals occuring as inclusions in plagioclase $(\mathrm{Pl})$ crystals and as apatite microphenocrysts in contact with matrix glass, from trachydacitic pumices of both the climactic 1257 eruption and an earlier 2550 B.P. event ${ }^{3}$. The lowest $\delta^{34} \mathrm{~S}_{(\mathrm{CDT})}$ value observed in all four sample groups is $8.5 \%$, which we interpret as representative of evolved magmas entering the sub-volcanic system. Pl-hosted apatite inclusions from the 1257 eruption range up to a $\delta^{34} \mathrm{~S}_{\text {(CDT) }}$ of $11 \%$, while microphenocrysts reach $16 \%$, consistent with inclusions capturing an earlier stage of magma evolution. While Pl-hosted inclusions show no clear correlation between $\delta^{34} \mathrm{~S}$ and $\mathrm{S}$ counts per second (CPS, as a rough proxy for concentration), microphenocrysts display a negative correlation, with lower S CPS coupled to higher $\delta^{34} \mathrm{~S}$ values. We tentatively interpret these observations to reflect a shift to higher $\delta^{34} \mathrm{~S}$ in the melt during degassing of sulfur. This interpretation is corroborated by zoned microphenocrysts that have low $\delta^{34} \mathrm{~S}$ values and higher CPS in their cores and high $\delta^{34} \mathrm{~S}$ values and lower CPS in their rims, with a maximum core-to-rim variation of $\sim 5 \%$ within a single apatite crystal.

${ }^{1}$ Sigl et al., 2015, Nature, ${ }^{2}$ Economos et al., 2017, G.C.A., ${ }^{3}$ Vidal et al., 2016, Sci. Reports 
This abstract is too long to be accepted for publication.

Please revise it so that it fits into the column on one page. 